\title{
Infraestructuras de paz y estatalidad en Colombia
}

\author{
Mauricio Uribe López*
}

Perfiles Latinoamericanos, 26(51)

2018 | pp. $167-189$

DOI: $10.18504 / \mathrm{pl} 2651-007-2018$

\section{Resumen}

Este artículo presenta un análisis del vínculo entre construcción de paz y construcción de Estado, apelando a las infraestructuras de paz como mecanismo articulador de ambos procesos a nivel territorial. Para ello, discute brevemente dos enfoques tecnocráticos de la construcción de paz: paz liberal y su giro institucional. El principal argumento es que las infraestructuras de paz articuladas a la gobernanza territorial resultan más apropiadas para promover sinergias entre construcción de paz y construcción estatal y que ellas brindan una perspectiva emancipadora y sostenible de la transición hacia la paz en Colombia.

\begin{abstract}
This article presents an analysis on the relationships between peacebuilding and statebuilding through infrastructures for peace as articulating mechanism between them at different territorial levels. It discusses briefly two technocratic approaches to peacebuilding: the liberal peace and its institutional turn. Infrastructures for peace linked to territorial governance end up being more suitable in order to promote synergies between peacebuilding and statebuilding. Infrastructures for peace give an emancipatory and sustainable view of transition towards peace in Colombia.
\end{abstract}

Palabras clave: construcción de paz, paz liberal, infraestructuras de paz, estatalidad, gobernanza territorial, Colombia.

Keywords: Peacebuilding, liberal peace, infrastructures for peace, statebuilding, territorial governance, Colombia.

* Doctor de Investigación en Ciencias Sociales con Mención en Ciencia Política por la Facultad Latinoamericana de Ciencias Sociales, Sede México. Profesor Titular del Departamento de Gobierno y Ciencias Políticas de la Universidad EAfiт (Medellín-Colombia) | muribel4@eafit.edu.co 


\section{Introducción}

na banda marcial es un sistema complejo de instrumentos, intérpretes, roles y funciones que avanzan hacia un destino acordado con un ritmo predeterminado. Un cuarteto de jazz también es un sistema complejo pero diferente: es un sistema adaptativo complejo. Con esa metáfora, John Paul Lederach ilustra la dinámica interdependiente, coherente y guiada pero también, en cierto modo, contingente, de los procesos de construcción de paz:

Miles Davis \& John Coltrane podrían interpretar Blue in Green cinco veces distintas en cinco diferentes noches, y en cada repetición emergería una estructura guiada por su música, y sin embargo cada presentación sería dinámicamente nueva y única. El Jazz funciona en un sistema adaptativo complejo (Lederach, 2012: p. 11).

La construcción de paz es un "concepto comprehensivo que abarca, genera y sostiene el conjunto completo de procesos, enfoques y etapas necesarias para transformar el conflicto hacia relaciones más sostenibles y pacíficas" (Lederach, 2010: p. 20). Requiere, por tanto, responder en forma creativa e interactiva a las necesidades de transformación de los conflictos, esto es, moldear actitudes, conductas y discursos de los actores hacia la expresión no violenta de las conflictividades, así como identificar bases mínimas de cooperación entre contradictores, orientadas a remover o modificar, en cada contexto, las características de la estructura social que acicatean la expresión violenta de tales conflictos.

Esa capacidad de respuesta de los procesos de construcción de paz supone el apoyo de infraestructuras de paz. De acuerdo con la definición adoptada en 2010 por representantes de los gobiernos y de actores de la sociedad civil de catorce países africanos reunidos a instancias del Programa de Naciones Unidas para el Desarrollo en Naivasha, Kenya, una infraestructura de paz es "una red dinámica de estructuras interdependientes, mecanismos, recursos, valores y habilidades, las cuales, a través de la consulta y el diálogo, contribuyen a la prevención del conflicto y a la construcción de paz en una sociedad" (Ryan, 2012: p. 15). Esas redes dinámicas apalancan la capacidad de los procesos de construcción de paz al brindar mecanismos (relaciones, coordinación, recursos) para promover cambios iniciados por negociaciones políticas y acuerdos de paz, involucrando activamente en ellos a las comunidades locales.

Se plantea aquí que la articulación entre infraestructuras de paz y gobernanza territorial brinda una oportunidad para potenciar sinergias entre las agendas de construcción de paz y construcción de Estado en Colombia. Esa oportunidad no está presente en enfoques tecnocráticos de la construcción de paz como el 
de la paz liberal centrada en la liberalización política y económica ni en el giro institucional de la paz liberal, el cual, tiende a reducir la construcción de paz a la construcción de Estado y este, a su vez, al diseño de las instituciones "correctas".

$\mathrm{El}$ artículo se divide en cinco secciones. La primera describe las complejidades de la transición hacia la paz, ubicando el caso colombiano en perspectiva internacional. La segunda parte presenta brevemente el paso de las operaciones de paz — en clave de paz negativa — a las misiones de paz —en clave de paz positiva- y el debate entre minimalismo y maximalismo del que deriva la pertinencia, para la construcción de paz, de la noción de gobernanza. Las secciones tercera y cuarta discuten los dos enfoques tecnocráticos de construcción de paz "de arriba hacia abajo": la paz liberal y el giro institucional. La quinta sección recorre algunas ideas sobre la articulación entre infraestructuras de paz y gobernanza territorial. Se incluye un comentario final.

\section{La difícil transición hacia la paz}

La existencia de competidores armados al interior de una unidad política es quizás el indicador más contundente de la debilidad de un Estado. Aunque no todos los Estados débiles han sido escenario de guerras civiles prolongadas, un Estado fuerte $^{1}$ con una guerra civil de larga duración sería una contradicción en esos términos. Colombia ha sido una democracia anómala, con una guerra larga y una marcada diferenciación territorial de la capacidad del Estado para arbitrar conflictos y garantizar la provisión de bienes públicos y meritorios. La base de datos sobre conflictos armados del Instituto Internacional de Investigación sobre Paz de Oslo (Prio, por sus siglas en inglés) y del Departamento de Paz e Investigación de Conflictos de la Universidad de Uppsala (UCPD) registra el conflicto armado en Colombia desde 1964. De acuerdo con los criterios establecidos en esa misma base, el conflicto en Colombia se puede clasificar como "guerra" desde 1980, año en que las hostilidades superaron — desde su inicioel número acumulado de mil muertes relacionadas con los combates.

En este artículo no se pretende dar cuenta del inicio y la prolongación de la guerra en Colombia. Sin embargo, es pertinente señalar que ambos procesos están relacionados con diversos mecanismos que vinculan, históricamente, dos categorías explicativas: estilo de desarrollo y estatalidad (Uribe, 2013a).

1 Un Estado fuerte no quiere decir un Estado grande. Un enorme aparato estatal puede no lograr establecer el imperio de la ley en todo su territorio. Un Estado fuerte en cambio es aquel que puede establecer esa legalidad y que "no es percibido por la población sólo como un ámbito para la persecución de intereses particularistas” (O’Donnell, 1993: p. 168). 
Esos mecanismos y procesos se han desplegado sobre una geografía compleja, con "más territorio que Estado". La guerra colombiana ha involucrado un amplio número de competidores armados del Estado. También ha dado lugar a varios procesos y acuerdos de paz hasta el punto que se puede afirmar que "Colombia es el único país en el mundo que ha hecho nueve negociaciones de paz y procesos de desmovilización de grupos armados ilegales en los últimos treinta ańos" (López, 2016: p. 313). Todos esos acuerdos —a pesar de ser exitosos en tanto que no se reanudaron las hostilidades entre las partes- han sido acuerdos parciales. ${ }^{2}$

Incluso a pesar de tratarse de la guerrilla más importante en la historia de la guerra colombiana, el acuerdo entre el gobierno y las Fuerzas Armadas Revolucionarias de Colombia (FARC), es un acuerdo parcial. Su éxito puede considerarse como condición necesaria para asegurar la transición hacia la paz. Sin embargo, no es condición suficiente en la medida en que otros grupos como el Ejército de Liberación Nacional (ELN) persistan en su desafío armado contra el Estado. Adicionalmente, la terminación del conflicto armado tampoco es condición suficiente para garantizar la paz en su sentido negativo. ${ }^{3}$ La experiencia internacional muestra que los conflictos armados alientan dinámicas violentas difíciles de revertir una vez que han terminado.

Keen (1998) destaca el papel que juegan los intereses económicos que maduran durante las guerras y que están relacionados no solo con el comportamiento predatorio de los actores armados orientado a financiar los esfuerzos de la guerra, sino también con los medios de vida que los encadenamientos económicos de la guerra misma generan para sectores de la población involucrados directa o indirectamente en actividades conexas o de apoyo (redes de suministros, tráfico de bienes ilegales o comercio ilegal de bienes legales, cultivos ilícitos, etc.). Esos intereses no desaparecen automáticamente con un acuerdo de paz. Newman $\&$ Keller (2007) ilustran este argumento con los casos de Bosnia y Afganistán tras

2 Un acuerdo es parcial en los siguientes dos casos: $i$ ) cuando una o algunas organizaciones guerrilleras firman un acuerdo de paz con el gobierno, mientras otras se mantienen en guerra, y $i$ ) cuando una organización guerrillera se escinde durante un proceso de paz de modo que una facción opta por el acuerdo y la otra continúa en la guerra (Nasi, 2007: p. 40).

3 La paz negativa corresponde a la ausencia de violencia personal y directa en la que hay un agente, un sujeto claramente identificable, que causa daño a otro, reduciendo así sus realizaciones efectivas. En la violencia directa está clara la tríada sujeto-objeto-acción. La paz negativa se diferencia de la paz positiva en tanto que la segunda implica la ausencia de violencia estructural. Según Johan Galtung, la violencia puede ser entendida como aquella influencia que aumenta la brecha entre las realizaciones efectivas y las realizaciones potenciales de las personas. En el caso de la violencia estructural, esa brecha es producida por la desigualdad en la distribución de los recursos en la sociedad y, fundamentalmente, por la desigualdad en el poder de decidir sobre la distribución de tales recursos. En la violencia estructural no hay un agente claramente responsable dado que se trata de una violencia producida por los sistemas (económico, social, cultural y político) en los que los sujetos interactúan (Galtung, 1969). 
los acuerdos de Dayton (1995) y Bonn (2001). En Bosnia, la economía informal representa la mitad del producto interno bruto y se estima que el $40 \%$ de la población desempleada depende de medios de vida clandestinos. Los acuerdos de Dayton (1995) y las políticas de construcción de paz postacuerdo no incluyeron ese tema, de modo que la economía subterránea como fuente de violencia persiste. En Afganistán, la alianza establecida en el acuerdo de Bonn para la puesta en marcha de la agenda antitalibán permitió el empoderamiento de los señores de la guerra (Alianza Norte y otros grupos) basado en el crecimiento del número de hogares vinculados al cultivo de opio.

De acuerdo con la senadora Claudia López, solamente la guerrilla de las FARC ha llegado a emplear a unas 65 mil familias cocaleras. En consecuencia, no se trata simplemente de desmovilizar a los guerrilleros y a sus milicianos y allegados, sino de ofrecer a decenas de miles de colombianos en las zona rurales y vinculados a la economía de la guerrilla "otras fuentes de ingreso y regulación de su vida y desarrollo territorial que no sean las que ofrecían las Farc o las que podría ofrecer otro ilegal" (López, 2016: p. 43).

En Uribe (2013b) encontré, al comparar situaciones de conflicto y "posconflicto" ${ }^{4}$ en África y América Latina después de la guerra fría, que ninguno de los casos de "posconflicto" podía catalogarse como "posconflicto no violento", definiendo esa categoría como aquella situación en la que la guerra ha terminado con la firma de un acuerdo de paz y la tasa de homicidios es inferior a su nivel epidemiológico. ${ }^{5}$ Si se tiene en cuenta que la paz negativa no depende solo de la ausencia de competidores armados del Estado sino también de la seguridad ciudadana, es indispensable contar con un Estado capaz de proveer ese bien público. Sin embargo, las condiciones para el ejercicio de esa capacidad resultan dramáticamente erosionadas en sociedades que han sido escindidas por guerras internas.

En Guatemala, por ejemplo, el involucramiento durante 36 años de los aparatos coercitivo y judicial del Estado en la guerra contra la Unión Revolucionaria Nacional Guatemalteca (URNG), dejó una impronta institucional contrainsurgente en el sector de seguridad y justicia que ha sido difícil de remover luego del acuerdo de paz firmado en 1996 (Torres, 2012). Esa impronta se tradujo

4 Uso la palabra "posconflicto" entre comillas por considerar que, si bien su uso es frecuente en la literatura académica y en el lenguaje político cotidiano, se trata de un término equívoco en la medida en que el conflicto cumple funciones de socialización e integración social de modo que -como señala Robert Dahl— en las democracias el conflicto es no solo normal sino también saludable (Paris, 2004: p. 157).

5 "Los especialistas coinciden en que un escenario de cinco homicidios por cada 100000 habitantes al año es considerado normal, entre cinco y ocho homicidios es alarmante, lo cual requiere repensar las políticas, y más de ocho constituye una tasa epidémica, lo que significa que el fenómeno es parte de estratos muy profundos de la realidad social y exige un cambio de paradigmas" (Kliksberg, 2008: p. 7). 
en la tendencia sistemática de dejar de lado consideraciones relativas a los derechos humanos en los operativos de seguridad, lo que hizo que sus resultados fueran adversos. ${ }^{6}$ Adicionalmente, la extrema debilidad fiscal que caracterizó a Guatemala durante la guerra, aunque levemente atenuada, ha persistido luego de la firma del acuerdo de paz, limitando seriamente la capacidad del Estado guatemalteco en el posconflicto. $^{7}$

En Colombia, la terminación del conflicto armado con las FARC sería apenas el comienzo de un largo proceso de transición hacia la paz. El país tiene una democracia anómala o una "semidemocracia" no tanto por restricciones impuestas a la participación política "desde arriba" sino por las limitaciones relacionadas -en un contexto de conflicto armado- con la protección de los derechos y libertades civiles (Bejarano \& Pizarro, 2005), y por la incapacidad del Estado para asegurar la implementación, en todo el territorio, de decisiones de política pública tramitadas —en general— respetando procedimientos democráticos. Colombia pertenece a la primera categoría en la tipología propuesta por Tilly (2007): i) democracias con baja capacidad estatal, ii) democracias con alta capacidad estatal, iii) regímenes autoritarios con baja capacidad estatal, y iv) regímenes autoritarios con alta capacidad estatal. Muchos otros países también pertenecen a la primera categoría y no han experimentado una guerra interna. Sin embargo, en los casos en los que - como en Colombia y Guatemala - guerra y debilidad estatal han sido concomitantes, viene a ser difícil ignorar cierta complementariedad entre la agenda de construcción de Estado y la agenda de construcción de paz.

No obstante, como advierte Call (2008), la existencia de tensiones entre ambas agendas (las cuales se plantean en la sección "Construcción de paz y construcción de Estado"), impide considerar ambos términos como intercambiables o reducir la construcción de paz a la construcción de Estado. No siempre esa complementariedad se ha tomado en cuenta. De hecho, las misiones de paz llevadas a cabo durante la década de los noventa pasaron por alto esa complementariedad, dando así lugar al primero de los enfoques tecnocráticos de construcción de paz: la paz liberal o wilsoniana. Antes de presentar la noción de paz liberal, uno de los principales enfoques tecnocráticos de la construcción de paz, vale la pena detenerse en el tránsito de la paz negativa a la paz positiva que tuvo lugar con la ampliación

6 Por ejemplo, el gobierno de Alonso Portillo (2000-2004), quien fue extraditado a los Estados Unidos en 2012 por acusaciones relacionadas con lavado de activos, puso en marcha, como parte de una política de mano dura contra la delincuencia, el llamado Plan Escoba. Según cifras de la United Nations Office on Drugs and Crime (UNODC), al comenzar el gobierno de Portillo, la tasa de homicidios en Guatemala era de 25.8 por cada cien mil habitantes. Al terminar su gobierno era de 36.3 homicidios por cada cien mil habitantes.

7 De acuerdo con los indicadores de desarrollo del Banco Mundial, los ingresos tributarios representaban el 6.86\% del piв de Guatemala en 1990. En 2000 llegaron al 10\% y en 2008 al 11.3\%. 
de las intervenciones, en contextos de conflicto y "posconflicto", basadas en las operaciones de mantenimiento de paz, a las misiones de construcción de paz con una intervención multilateral y multidimensional mucho más amplia.

\section{Del paso de lo "negativo" a lo "positivo" en el tránsito del mantenimiento de la paz a la construcción de paz}

Durante la guerra fría terminaron 150 conflictos armados internos; un promedio de 3.5 conflictos por año. Posteriormente, entre 1990 y 2010 finalizaron otros 209 conflictos armados internos; un promedio de 8.7 conflictos por año. Tras la guerra fría, no solo aumentó el número de conflictos que terminaron con acuerdos de paz (cuadro 1), sino que también se amplió el margen de maniobra de las organizaciones internacionales para involucrarse en tareas de paz, más robustas que las tradicionales operaciones de mantenimiento de paz, las cuales "involucraban el despliegue de fuerzas equipadas con armamento ligero para monitorear un cese al fuego o, para patrullar zonas de amortiguamiento entre tropas previamente en combate" (Paris, 2004: p. 13).

En la Agenda por la Paz (1992), el entonces secretario general de Naciones Unidas reconocía que entre 1945 y 1989, el organismo había permanecido amordazado en la práctica para intervenir ampliamente a favor de la superación de las frecuentes guerras civiles. Durante ese periodo hubo 279 vetos impuestos por alguno de los miembros del Consejo de Seguridad. El final de la guerra fría permitió un papel mucho más intrusivo de Naciones Unidas, y de otros actores internacionales, debido a que aumentó "el margen para la cooperación entre los miembros permanentes del Consejo de Seguridad de Naciones Unidas" (Gizelis, Dorussen \& Petrova, 2016: p. 5).

\section{Cuadro 1. Tipos de terminación de conflictos armados internos}

\begin{tabular}{lrr}
\hline & $1946-1989$ & $1990-2014$ \\
\hline Acuerdos de paz & $10(6.6 \%)$ & $31(14.8 \%)$ \\
Cese del fuego & $7(4.6 \%)$ & $42(20.1 \%)$ \\
Total de acuerdos & $17(11.3 \%)$ & $73(34.9 \%)$ \\
\hline Victoria (Gobierno) & $62(41.3 \%)$ & $30(14.3 \%)$ \\
Victoria (Rebeldes) & $22(14.6 \%)$ & $9(4.3 \%)$ \\
Total de victorias & $84(56 \%)$ & $39(18.6 \%)$ \\
\hline Baja actividad & $45(30 \%)$ & $91(43.5 \%)$ \\
El actor deja de existir & $4(2.66 \%)$ & $6(2.9 \%)$ \\
Total & 150 & 209 \\
\hline
\end{tabular}

Fuente: Elaboración propia con base en Departamento de Paz e Investigación de Conflictos de la Universidad de Uppsala (UCDP). Conflict Termination Dataset versión 2-2015. 
El tránsito de las operaciones de mantenimiento de paz a una agenda de intervención mucho más amplia supone cierto desplazamiento desde una concepción estrictamente negativa de la paz (cese del fuego y de las hostilidades) ${ }^{8}$ hacia una visión de paz positiva que implica un conjunto de áreas de política pública que incluye, entre otras, desarme, desmovilización y reinserción de los excombatientes (DDR), justicia transicional y atención a víctimas, políticas de memoria y reconciliación, reformas al sector de seguridad y justicia, monitoreo del respeto y garantía de los derechos humanos, reformas electorales y de las instituciones políticas, educación y cultura para la paz, políticas poblacionales, y políticas de empleo e ingresos y desarrollo socioeconómico.

Con su ampliación, la agenda de construcción de paz ha corrido el riesgo de convertirse en una lista de mercado. ${ }^{9}$ Call $\&$ Cousens (2008) rechazan la concepción estrictamente negativa de la paz, a la que califican como minimalista, en la medida en que pasa por alto las características de cada contexto que aumentan el riesgo de reanudación de los conflictos. De hecho, el porcentaje de casos en los que se han reanudado las hostilidades es alto (cuadro 2), ${ }^{10}$ lo cual evidencia las limitaciones del estándar minimalista. Sin embargo, estos autores también critican la visión positiva de la paz asociándola con una visión que etiquetan como maximalista. Una visión maximalista de la paz conspira contra su utilidad analítica y práctica y dificulta la evaluación de prioridades.

Cuadro 2. Acuerdos de paz en conflictos internos 1975-2011, según reanudación de la violencia entre las partes cinco años luego de la firma

\begin{tabular}{llll}
\hline & Comprehensivos & Diádicos & Total \\
\hline Reanudación & $46(40.35 \%)$ & $31(37.80 \%)$ & $77(39.28 \%)$ \\
No reanudación & $68(59.64 \%)$ & $49(59.75 \%)$ & $117(59.69 \%)$ \\
No aplica (acuerdos firmados en 2010$)$ & - & $2(2.43 \%)$ & $2(1.02 \%)$ \\
Total & $114(100 \%)$ & $82(100 \%)$ & $196(100 \%)$ \\
\hline
\end{tabular}

Los acuerdos comprehensivos corresponden a los que se dan entre el gobierno y todos sus competidores armados; los diádicos a los se dan entre el gobierno y solo uno de sus competidores armados en un contexto de múltiples actores armados.

Fuente: Elaboración propia con base en UCDP Peace Agreement Dataset 1975-2011.

8 De acuerdo con esa concepción negativa o minimalista de la paz, George Downs y Sthepen Stedman señalan que para determinar el éxito o fracaso de una operación de paz hay que evaluar si cuando parten las agencias que intervienen en un contexto de posconflicto los fusiles están o no silenciados (Paris, 2004: p. 56).

9 "En vista de que las causas de los conflictos son múltiples, casi cualquier esfuerzo internacional de asistencia que aborde cualquier reclamo real o imaginario podría calificarse como construcción de paz" (Barnett et al., 2007: p. 44).

10 Una ilustración impactante del riesgo de recaída en los conflictos armados después de la firma de acuerdos de paz son los casos de Angola (Acuerdo de Bicesse en 1991) y Ruanda (Acuerdo de Arusha en 1993). En el primero, el número de muertes en los dos años posteriores a la firma de la paz superó la cifra alcanzada durante los dieciocho años de duración del conflicto previos al acuerdo (Paris, 2004: p. 67). Y el caso de Ruanda desembocó en el genocidio ocurrido entre abril y julio de 1994. 
No obstante, el concepto de paz positiva no es necesariamente maximalista. De hecho, Call \& Cousens (2008) plantean la necesidad de trascender la noción de paz negativa hacia lo que denominan — sin especificar en qué consiste"las bases de una gobernanza decente." Malone \& Nitzschke (2009) dan pistas para especificar ese concepto al identificar aquellas fallas de gobernabilidad que tienden a estar presentes en situaciones de conflicto armado. Esas fallas se expresan en i) gestión inadecuada de las políticas de desarrollo socioeconómico, ii) corrupción y particularismo en la provisión de bienes públicos y meritorios, y iii) acumulación de fuertes desventajas por parte de ciertos grupos poblacionales o habitantes de ciertas zonas geográficas en el acceso a las oportunidades económicas y políticas (desigualdades horizontales). ${ }^{11}$

Esos tres tipos de fallas de gobernabilidad evidencian complementariedades entre construcción de paz y construcción de Estado (relación que se discute en la sección correspondiente) y entre construcción de paz y desarrollo. En el debate sobre la relación entre construcción de paz y desarrollo también está presente un enfoque minimalista que considera la paz y el desarrollo en forma separada. Por ejemplo, Winrich Kuhne, del Instituto de Investigación sobre Asuntos Internacionales de Berlín afirma que "la construcción de paz es un esfuerzo de carácter político para responder a los problemas de seguridad, llevado a cabo durante un período limitado de tiempo, mientras que el desarrollo corresponde a una estrategia de largo plazo puesta en marcha generalmente, en condiciones de paz" (citado por Smoljan, 2003: p. 234).

Smoljan (2003) controvierte la visión minimalista estricta de Kuhne al plantear la necesidad de un enfoque integrado de construcción de paz y desarrollo que exige una mayor coordinación entre los diferentes actores involucrados y un mayor volumen de recursos financieros aportados por la comunidad internacional. Smoljan no afirma que construcción de paz y desarrollo sean sinónimos. Lo que hace es identificar áreas clave en esa relación, en particular las políticas de rehabilitación de la población afectada por la guerra y la necesidad de contar con políticas económicas y sociales compatibles con la construcción de paz. En

11 En un amplio análisis empírico de las dimensiones políticas y económicas de las desigualdades horizontales y su papel en el inicio y prolongación de las guerras civiles, Cederman, Gledisch \& Buhaug (2013) encuentran que aquellos grupos étnicos — aunque Stewart (2009) aclara que las identidades étnicas no es lo único que los define- con acceso limitado al poder estatal, o que experimentan pérdidas súbitas en el acceso a dicho poder, tienen más probabilidad de involucrarse en conflictos armados. Esto es más relevante para grupos grandes que para los pequeños. Así mismo, la desventaja económica aumenta la probabilidad de los grupos más pobres de involucrarse en una guerra civil. Cederman, Gledisch \& Buhaug evidencian que el vínculo entre desigualdades horizontales no es automático y que, por tanto, hay mecanismos que habilitan esa relación. Un mecanismo especialmente relevante es la debilidad del Estado. No obstante, aclaran que esa debilidad estatal no es un dato técnico neutral en la medida en que ella está interrelacionada con la exclusión de grupos enteros del acceso al poder. 
la misma línea, Nafziger \& Auvinen (2001: p. 21) señalan que la construcción de paz debe de incluir medidas orientadas a fortalecer y reestructurar la "economía política de los estados pobres, inequitativos y débiles."

El enfoque integrado entre paz y desarrollo respaldado por Smoljan se hace necesario para lidiar con los conflictos generados por los procesos de desarrollo económico y promover sinergias entre paz y desarrollo. Al igual que en el caso de la relación entre construcción de Estado y construcción de paz, también en la relación entre desarrollo y construcción de paz hay complementariedades y tensiones. Ambos tipos de complementariedades y tensiones no parecen haber sido tomadas adecuadamente en consideración por el enfoque de la paz liberal.

\section{Los avatares de la paz liberal}

El término paz liberal hace referencia a la corriente de pensamiento y a las políticas dominantes puestas en práctica en las intervenciones en casos de "posconflicto" llevadas a cabo luego de la guerra fría (Sabaratnam, 2011: p. 13). Aunque no corresponde necesariamente a un conjunto único y consistente de supuestos e ideas, representa, en general, la noción según la cual el mejor antídoto para evitar la reanudación de los conflictos armados internos es la promoción de la democracia liberal y de la economía de mercado en sociedades en transición hacia la paz.

La paz liberal —-heredera de la perspectiva idealista de las relaciones internacionales promovida por el presidente Woodrow Wilson- extiende la hipótesis sobre la baja probabilidad de guerras entre países democráticos al caso de las guerras civiles ${ }^{12}$ planteando, en sus intervenciones, que la mejor manera de evitar una recaída en el conflicto armado es mediante la puesta en marcha — con celeridad - de reformas orientadas hacia la democratización de los regímenes políticos y la liberalización de la economías de los países en "posconflicto".

La paz liberal se convirtió en "una de las más influyentes de las doctrinas de la posguerra fría” (Ryan, 2013: p. 27), en parte como resultado de dos grandes cambios ocurridos en lo que los partidarios de la escuela neoinstitucionalista del sistema internacional llamarían la "cultura global" —o el conjunto de reglas formales e informales de dicho sistema- en la década de los noventa. El primero de estos cambios está relacionado con la tercera ola de democratización (Hunt-

12 Ryan (2013) cuestiona la extensión de la hipótesis de la paz democrática entre Estados al caso de las guerras civiles, señalando no solo la escasez de evidencia empírica para la validación de dicha extensión, sino también el simplismo con el que se postuló el nexo entre paz y democracia. Simplismo que estuvo presente, por ejemplo, en las intervenciones estadounidenses en Irak y Afganistán. 
ington, 1991). Como afirma Ryan (2013: p. 27), la cadena de revoluciones democráticas no violentas generalizó la idea de que la promoción de la democracia en contextos de "posconflicto" estaba en sintonía con la corriente de la historia. En consecuencia, se pensaba que podía llevarse a cabo en forma rápida y exitosa.

El segundo de estos grandes cambios corresponde al giro neoliberal de las políticas de desarrollo económico en la década de los noventa. Aunque la Agenda por la Paz estableció las bases ideológicas y políticas para justificar las intervenciones multilaterales y multidimensionales de la década de los noventa (Sabaratnam, 2011), el enfoque de Boutros-Ghali no se inclinaba explícitamente hacia la liberalización económica. El documento planteaba una visión de la construcción de paz como el conjunto de esfuerzos orientados a "identificar y apoyar aquellas estructuras que tenderán a consolidar la paz y promover un sentido de confianza y bienestar entre la gente" (Boutros-Ghali, 1992, párr. 55) y asumía, por tanto, a Naciones Unidas como un agente promotor de la paz, el desarrollo y la justicia social. ${ }^{13}$ Sin embargo, la participación de las instituciones financieras internaciones en las misiones de construcción de paz contribuyó a inclinar esas intervenciones hacia una visión más acorde con la tríada del Consenso de Washington de liberalización económica, privatización y ajuste fiscal. Una inclinación ciertamente problemática en contextos de marcada endeblez del aparato estatal.

Asimismo, no siempre los objetivos liberales ${ }^{14}$ de las misiones de construcción de paz se han visto reflejados en sus prácticas. Las actuaciones en terreno —afirma Ryan — no siempre tienden a apoyar convicciones liberales y pueden terminar involucradas en desarrollos que difieren bastante por cuenta de intereses políticos particulares y cálculos autointeresados, cortoplacistas o de reducción de costos. De hecho, este autor concluye que "uno no tiene que ser realista para considerar la advertencia de que gobiernos que se casan con los ideales liberales pueden usarlos como ropaje para promover sus razones menos altruistas" (Ryan, 2013: p. 33).

Pero incluso, independientemente del grado de adhesión de las prácticas a los principios y propósitos declarados en las misiones de paz, los resultados pueden terminar siendo iliberales, no tanto por distorsiones en la implementación sino por fallas presentes en los supuestos mismos del enfoque de la paz liberal. Esto es precisamente lo que indaga Paris (2004) en el análisis de catorce

13 Sabaratnam (2011) destaca que esta visión se vería reforzada en los documentos Agenda por el Desarrollo (1994) y Un Suplemento a la Agenda por la Paz (1995) de Boutros-Ghali, así como por la Cumbre Mundial sobre Desarrollo Social llevada a cabo en Copenhague en 1995.

14 "Así como el liberalismo puede ser enérgico y coercitivo, es también capaz de construir una narrativa muy atractiva de emancipación y progreso. La retórica liberal dibuja un cuadro de individuos autónomos y comunidades libres para seguir su propio curso de vida, con la protección brindada por una pluralidad de mecanismos" (Mac Ginty, 2011: p. 213). 
misiones de construcción de paz ${ }^{15}$ realizadas entre 1989 y 1999. La estrategia de rápida liberalización — política y económica — se tradujo en un tipo específico de ingeniería social orientada hacia la promoción de derechos civiles y políticos, alistamiento de elecciones, capacitación de jueces y policías, aprobación de textos constitucionales, promoción de la sociedad civil, transformación de actores armados en actores políticos y liberalización económica.

La súbita promoción de derechos civiles y políticos como la libertad de prensa - sin estrategias para morigerar los discursos de odio- condujo a experiencias como la de la Radio de las Mil Colinas en Ruanda, cuyas transmisiones incitaron a la violencia contra los tutsis, lo cual, aunado a otros factores, desembocó en genocidio. El frenesí electoral provocó que en Angola se celebraran votaciones sin haber completado el proceso de desarme de la Unión para la Independencia Total de Angola (UNITA), de modo que las acusaciones de fraude en octubre de 1992 reanudaron un nuevo episodio de la guerra que causó trescientas mil muertes en tres años. La debilidad en las instituciones de seguridad y justicia ha facilitado la interferencia del crimen organizado en ambos sectores en Guatemala. La liberalización económica y los programas de ajuste no solo han exacerbado tensiones sociales, sino que han erosionado la capacidad fiscal de los Estados para ejercer sus funciones.

El problema del enfoque wilsoniano radica, en el análisis de Paris, en promover la construcción de paz por medio del conflicto sin diseñar las reglas apropiadas para regularlo y garantizar la aplicación de las mismas. La competencia política y la competencia en el mercado no se autorregulan: "La competencia tiene lugar en un marco institucional que resuelve disputas, traslada el debate público a las políticas públicas y aplica un sistema de reglas y regulaciones que gobiernan la operación de la comunidad política y la economía" (Paris, 2004: p. 159).

La premura por implementar reformas políticas y económicas para transformar — de la noche a la mańana — a países recientemente devastados por la guerra, condujo a lo que Paris denomina patologías de la liberalización. De las cuales, entre las más significativas se hallan: el afianzamiento de expresiones de "mala sociedad civil" (organizaciones que promueven el fundamentalismo y el extremismo); elecciones como punto focal de una competencia dañina; transiciones saboteadas y fallidas, y tensiones exacerbadas por la liberalización económica, la que a su vez limita el margen de maniobra de los Estados para lidiar con esas tensiones y atender los compromisos del "posconflicto". Esas patologías evidencian que el Leviatán estuvo ausente en las misiones de paz. Como afirma

15 Namibia (1989), Nicaragua (1989), Angola (1991), Camboya (1991), El Salvador (1991), Mozambique (1992), Liberia (1993), Ruanda (1993), Bosnia (1995), Croacia (1995), Guatemala (1997), Timor Oriental (1999), Kosovo (1999), Sierra Leona (1999). 
Paris, el wilsonianismo pasó por alto al Estado. Con ello, los promotores de la paz liberal olvidaron lo que filósofos de la Ilustración como John Locke tenían bastante claro: que un gobierno limitado no es lo mismo que un gobierno débil.

\section{Construcción de paz y construcción de Estado}

Paris (2004) no solo señala las falencias de las estrategias de liberalización económica y política apresuradas y alentadas por los responsables de las misiones de paz en la década de los noventa, sino que propone reorientar la construcción de paz hacia la construcción de instituciones apropiadas para lidiar con los riesgos y tensiones que surgen en los procesos de transición de la guerra a la paz. Paris sugiere un giro institucional de la construcción de paz con la fórmula: "Institucionalización antes que Liberalización". Dicha fórmula implica cosas como: esperar a que las condiciones sean apropiadas para llevar a cabo elecciones, diseñar sistemas electorales que incentiven la moderación, promover una "buena sociedad civil", controlar los discursos de odio, poner en marcha políticas económicas que no exacerben el odio, y construir instituciones estatales efectivas. Este último punto de la agenda de la "Institucionalización antes que Liberalización" es quizá el más significativo pero también el más complejo del giro institucional.

El reconocimiento de la construcción estatal y de la construcción institucional, como dimensiones fundamentales y complementarias de la construcción de paz, ha hecho del "diseño de las instituciones correctas" una suerte de mantra contemporáneo de los constructores de paz. Hay en la actualidad un acuerdo bastante amplio sobre la necesidad de contar con Estados que funcionen gracias a las instituciones apropiadas para prevenir y arbitrar, pacíficamente, los conflictos entre diferentes grupos sociales y sus expresiones políticas. "Las instituciones - ampliamente definidas como las reglas de juego y las organizaciones que las enmarcan y las hacen cumplir- brindan los incentivos y los límites que moldean la interacción política, económica y social”, afirmó el secretario general de Naciones Unidas, Ban Ki-Moon (2012, párr. 43). Y añade: "la construcción institucional es un pilar central de la paz sostenible". Se trata de una perspectiva que reconoce — al igual que Paris - las limitaciones de la tesis de la paz liberal y que avala el giro institucional en las misiones de paz.

El Estado, en tanto conjunto de instituciones que reivindican - haciendo eco de la definición weberiana - el monopolio de la autoridad legítima ${ }^{16}$ y el uso de

16 No obstante, es necesario reconocer que la "legitimidad es una cosa extraña, una sobre la cual tenemos poco conocimiento sólido e inmediato” (Call, 2008: p. 71). 
la fuerza sobre un territorio, es necesario en un contexto de "posconflicto" porque alguna autoridad debe hacerse responsable de mantener el orden, proveer servicios y arbitrar conflictos (Call, 2008). De hecho, hay tres áreas fundamentales de intersección entre construcción de paz y construcción de Estado: seguridad, finanzas públicas (tributación y gasto) y administración de justicia. Sin embargo, es indispensable reconocer que construcción de Estado y construcción de paz no son sinónimos y que existen tensiones entre ambos procesos (cuadro 3).

Cuadro 3. Charles Call: tensiones entre construcción de Estado y construcción de paz

\begin{tabular}{l}
\hline Enunciado \\
\hline "La construcción de Estado puede gene- \\
rar o facilitar el conflicto armado, especial- \\
mente si el Estado que emerge es dotado \\
de muchos poderes demasiado rápido" \\
(p. 63).
\end{tabular}
Ilustración (ejemplos)

Somalia 2004: actores internacionales empezaron a tener cierto éxito en el levantamiento de cierta estatalidad. El proceso generó resistencia armada por parte de aquellos clanes que fueron ignorados o que vieron amenazada su autoridad. Si se hubiera mantenido el reconocimiento de cierta autoridad para los clanes, es posible que no se hubiera disparado la violencia. El caso de Afganistán difiere del de Somalia en la medida en que el acuerdo de Bonn (2001) condujo a un proceso gradual de consultas con representantes regionales y señores de la guerra opuestos a los talibanes, lo que contribuyó a hacer viable a la administración de Hamid Karzai.

"La construcción de paz llevada a cabo por actores internacionales socava la construcción de Estado cuando elude a las instituciones estatales, incluso si dicha elusión tiene sentido" (p. 64).

La meritocracia "debe ser sopesada con principios del logro de la paz — como soluciones de compromiso y medidas para compartir el poder-con el propósito de que la paz sobreviva mientras se hace posible la construcción de Estado" (p. 65)

"Ir demasiado lejos en una dirección -enfocándose en un solo criterio de fortalecimiento de las capacidades del Estado- sin prestar atención a cuestiones relativas a la inclusión política, la rendición de cuentas y otros procesos políticos, puede desembocar en violaciones de derechos humanos, exclusión política, deslegitimación del Estado e incluso, guerra" (p. 65).

Ir demasiado lejos en el apaciguamiento de saboteadores en el interés de la paz puede fortalecer a actores autoritarios que ponen en peligro tanto a la paz como al Estado.
Casos de insistencia en: entregar ayudas en forma directa (sin intervención del Estado), rendir cuentas solo a los donantes, evitar decisiones domésticas y mantener dependencia de contratistas provenientes de los países donantes o de ONG internacionales. Bosnia ilustra las consecuencias negativas de largo plazo de una misión internacional cuyos poderes sobrepasan los de funcionarios electos. Un mecanismo para reducir la corrupción en Estados en "posconflicto" no es tanto ignorarlos sino promover mecanismos de rendición de cuentas combinando en las operaciones actores internacionales y gubernamentales.

Centrarse exclusivamente en el objetivo de construir burocracias eficientes y apolíticas genera dificultades cuando existe la necesidad de incorporar funcionarios que representen diferentes facciones - incluso si no son las más cualificados-. "Las exigencias de la paz, en consecuencia, pueden producir un tipo de Estado algo diferente del estrictamente 'meritocrático', altamente valorado por los programas técnicos internacionales. Los complicados arreglos multinivel para compartir el poder en Bosnia son un ejemplo de esto" (p. 65). Sin embargo, es posible combinar medidas orientadas a asegurar representación de diferentes grupos con incentivos basados en criterios meritocráticos que pueden aplicarse gradualmente.

Es una tensión relevante en el caso de la reforma del sector de seguridad, especialmente en situaciones en las que la población civil ha padecido abusos por parte de las fuerzas de seguridad del Estado.

Fuente: Elaboración propia con base en Call (2008)

Ahora bien, incluso en las tres áreas fundamentales de intersección mencionadas, es necesario tomar en cuenta que el Estado es tanto parte de la solución como del problema de la construcción de paz. Ello porque la estatalidad —y los 
intereses que representa — es en sí misma caleidoscópica: existe en múltiples niveles y sectores con diferentes agencias y funcionarios sujetos a la presión de diversos intereses. En consecuencia, al interior de un Estado existe una abigarrada mezcla de prácticas y actores en función del grado de fragmentación de la sociedad. Así las cosas, "las dificultades en la implementación de políticas, el cálculo de las presiones sobre el implementador, la captura de los tentáculos del Estado... derivan de la estructura fragmentada de la sociedad" (Migdal, 2001: p. 93). El "enfoque del Estado en la sociedad" de Joel Migdal sostiene que la estatalidad es un conjunto de arenas de disputa política entre actores:

[El Estado] no genera una sola, homogénea respuesta a un asunto o problema, ni siquiera un conjunto necesariamente variado pero coordinado de respuestas. Más bien, sus resultados — la formulación e implementación de sus políticas— son series de acciones diferentes basadas en el cálculo particular de las presiones que cada componente comprometido del Estado enfrenta en su ámbito particular de actuación. Esos ambientes de actuación, los lugares de conflictos y coaliciones, de presión y de apoyo que involucran partes del Estado y otras fuerzas sociales, son lo que hemos denominado las arenas de dominación y oposición (Migdal, 2001: pp. 116 -117). ${ }^{17}$

Adicionalmente al problema del carácter caleidoscópico de la estatalidad está la cuestión misma de la concepción sobre las instituciones. Afirmar que la construcción de paz se reduce a la construcción institucional conlleva el riesgo de concebir ambos procesos simplemente en términos de diseño de la arquitectura institucional apropiada. Esa concepción inspira el segundo enfoque tecnocrático de la construcción de paz: la construcción de paz como ingeniería institucional y como un proceso que consiste simplemente en "llevar" el Estado a las regiones. De hecho, la investigadora y senadora Claudia López descarta apropiadamente la pertinencia de ese enfoque tecnocrático para la construcción de paz en Colombia:

Superar la enorme presencia diferenciada del Estado en las regiones supone entender que el Estado es un orden social e institucional que se construye a partir de las demandas políticas que los ciudadanos logren hacer valer en el debate público y

17 Migdal (2001) distingue cuatro niveles de organización estatal en los que se despliegan esas arenas de dominación y oposición: $i$ ) funcionarios del nivel local que tratan directamente con diversas fuerzas sociales (recolectores de impuestos, maestros, oficiales de policía, etc.), ii) los burócratas de rango medio que organizan la ejecución de una política pública en una región, iii) las cabezas de las agencias estatales expuestas a presiones de intereses del nivel nacional: medios de comunicación, organizaciones religiosas, grandes grupos empresariales, inversionistas y gobiernos extranjeros, etc., y iv) el pináculo del poder político: altos mandos y élites estatales en las diferentes ramas del poder público. 
electoral a sus gobernantes, y a partir de la economía política de cada región, por lo cual no se puede "llevar a las regiones" a pesar de y desconociendo, o sometiendo, las demandas de la población de las regiones y sus formas locales de organización, poder y representación (López, 2016: p. 42).

Por otra parte, es necesario tener en cuenta que las instituciones no son solamente reglas de juego diseñadas racionalmente mediante un "acuerdo de voluntades". Las instituciones también son "procedimientos formales e informales, rutinas, normas y convenciones" que están "incrustadas en la estructura organizacional de la comunidad política o de la economía política" (Hall \& Taylor, 1996: p. 938). "Son productos desarrollados a partir de luchas entre actores desiguales” (Pierson \& Skocpol, 2008: p. 19).

Ciertamente, los diseños institucionales importan. Por ejemplo, no es lo mismo en una situación de "posconflicto" introducir reglas electorales del tipo mayoritario que no ofrecen mayor opción de representación política a las minorías, que plantear reglas de tipo proporcional orientadas a la dispersión del poder o al menos, a la adopción de algún tipo de circunscripción especial para la participación política de las guerrillas convertidas en partidos. Pero reducir la construcción de paz al diseño de las instituciones "correctas" como si existiera un solo conjunto de instituciones apropiadas, una receta institucional única sin tomar en cuenta el contexto y las interacciones entre reglas formales y reglas informales ${ }^{18}$ es un camino abierto a los efectos indeseados.

También es importante aclarar que las únicas instituciones que importan no son las de los derechos de propiedad y las garantías para el cumplimiento de los contratos. De hecho, "la fuerte protección de los derechos de propiedad de los terratenientes ha demostrado ser nociva para el desarrollo económico, no en todos pero sí en muchos países" (Chang, 2010: p. 9). No es que los derechos de propiedad no importen, pero es indispensable reconocer que existen diferentes tipos de derecho de propiedad que corresponden a distintas reglas de acceso, retiro, administración, exclusión y enajenación creadas al interior de las comunidades (Ostrom, 2009). Igualmente es necesario no centrarse exclusivamente en la causalidad que va de las instituciones al desarrollo y a la características de cada contexto social, sino además reconocer que hay una causalidad que va de los procesos de desarrollo al surgimiento y cambio de las instituciones tal y como lo

18 "Definimos instituciones informales como aquellas reglas socialmente compartidas, generalmente no escritas, que son creadas, comunicadas y reforzadas por fuera de canales oficiales. En contraste, definimos instituciones formales como aquellas reglas que son abiertamente codificadas, en el sentido en que son establecidas y comunicadas a través de canales ampliamente aceptados como oficiales" (Helmke \& Levitski, 2004: p. 5). 
muestra Chang (2010). De hecho, "el desarrollo económico crea nuevos agentes de cambio que demandan nuevas instituciones" (Chang, 2010: p. 4).

En síntesis, construir el Estado no es un problema de mero diseño institucional. De hecho, el término mismo construcción de Estado es problemático en el sentido de que el Estado nación europeo, históricamente el primero en su tipo, no fue el resultado de ningún diseño deliberado (Tilly, 1992). La infraestructura estatal es algo que se apoya más en la realidad de la periferia que en las imágenes del centro. En contextos de alta fragmentación social y territorial como el colombiano, existe la necesidad de avanzar hacia dos objetivos aparentemente incompatibles: por un lado, la promoción de un grado significativo de centralización política, y por el otro, la construcción de una estatalidad multinivel que reconozca las reivindicaciones y las formas locales de organización y representación.

El propósito de la centralización política se relaciona con la capacidad del Estado para asegurar el cumplimiento de la ley y el arbitraje de los conflictos en todo el territorio, de modo que no haya margen ni para los competidores armados ni para los poderes de facto que operan en aquellas áreas geográficas en las que la legalidad es menos efectiva y los gobiernos locales están fundamentados sobre bases fuertemente personalistas y clientelistas (O’Donnell, 1993). Se relaciona también con la existencia misma de la comunidad política nacional. La cuestión nacional parece ser una condición de fondo de la construcción estatal en contextos de "posconflicto". Una cuestión que tiene que ver con la transformación de la enemistad en amistad política o al menos, la relativización de esa enemistad.

Esa amistad política como condición de fondo de la estatalidad simplemente significa que la amplia mayoría de los ciudadanos "no han de tener dudas o reservas mentales acerca de a cuál comunidad política ellos pertenecen" (Even Dankwart Rustow, citado por Goetze \& Guzina, 2008: p. 325). La construcción nacional se entiende como "las acciones llevadas a cabo, usualmente por actores nacionales, para forjar un sentimiento común de nacionalidad, para evitar las diferencias étnicas, sectarias o comunitarias y contrarrestar fuentes alternativas de identidad y lealtad, y para movilizar a la población a favor de un proyecto paralelo de construcción estatal" (Call \& Cousens, 2008: p. 4).

La construcción de una estatalidad multinivel resulta compatible con la intuición acerca de que es plausible considerar que esa condición de fondo, el fomento de la ciudadanía como una identidad compartida, es más compatible con el ejercicio político emancipador y elicitivo desde lo local y lo regional, que con la perspectiva prescriptiva y tecnocrática de llevar el Estado desde el centro a la periferia. La construcción de paz y la construcción de Estado encuentran, en esta perspectiva multinivel, una oportunidad para morigerar tensiones y promover sinergias a partir de la articulación entre infraestructuras de paz y la cuestión de la gobernanza territorial. 


\section{Infraestructuras de paz y gobernanza territorial}

Lederach (2010) explica que hay al menos tres niveles en los procesos de construcción de paz: el nivel de las élites nacionales y de los actores internacionales, el de las organizaciones de base y las comunidades locales, y el nivel intermedio en el que hay actores cercanos a los líderes de las organizaciones de base y a las élites. Ese nivel meso en términos de actores corresponde a un nivel meso en términos territoriales.

La escala de lo territorial varía de acuerdo con las formas que asume en cada caso la relación entre territorio, población y bienes (públicos, meritorios y comunes). Corresponde a lo que Fals (1999) denominaba el "bioespacio", es decir, el lugar de la vida de las comunidades, en el entendido de que estas se encuentran anidadas en diferentes niveles: desde la comunidad local de la vereda o el municipio y la comunidad de los habitantes de una cuenca hidrográfica, hasta la comunidad política conformada por quienes han desarrollado un sentido de pertenencia a la misma nación. La noción de gobernanza territorial se relaciona con la idea de múltiples comunidades espaciales de interés que parten desde lo local y múltiples capas de organización de la estatalidad acorde con estas (Chandler, 2010). Esas capas encajan con el enfoque multinivel de la construcción de paz. En el nivel intermedio, los principales actores son individuos e instituciones con cierta cercanía con las bases y con algún tipo de influencia en los ámbitos nacional e internacional.

Aunque existen avances normativos y esfuerzos de asociación territorial en Colombia, sigue pendiente ordenar el territorio en torno a las provincias y las regiones: "La Provincia como coordinación de municipios afines (aún de diferentes departamentos) que combinan proyectos, recursos y voluntad política, puede contribuir a la solución de conflictos al asegurar el buen gobierno en un nivel superior y más amplio de espacio territorial” (Fals, 1999: p. 94). Adicionalmente, la región entendida como agrupación de departamentos que comparten un mismo proyecto histórico de desarrollo y que pueden asumir parte de las estructuras, recursos y funciones de las entidades nacionales, permitirían plantear en forma mucho más realista la idea de construir las capacidades del Estado en las propias regiones en lugar de la idea tecnocrática de "llevar" el Estado a la periferia. Provincias y regiones configuran un nivel intermedio apropiado para establecer infraestructuras de paz, las cuales pueden estar conformadas - aunque no de manera exclusiva - por instancias de participación en la planeación del desarrollo en esos mismos niveles. El papel atribuido a los Consejos Territoriales de Planeación, en el acuerdo de paz con las FARC, podría convertirlos en pivotes de las infraestructuras provinciales y regionales de paz.

La literatura sobre infraestructuras de paz ha puesto el énfasis en instancias formales e institucionalizadas con la participación de representantes de la socie- 
dad civil y del Estado en los diferentes niveles territoriales, tales como consejos nacionales y subnacionales de paz y comités locales (Pfeiffer, 2014; Odendaal, 2012). No obstante, una interpretación amplia de las infraestructuras como plataformas dinámicas (Lederach, 2012), más que como instituciones o comités de paz puede - manteniendo su fidelidad a la definición de Naivasha—incluir las instancias de participación en los procesos de planeación del desarrollo en distintos niveles de un ordenamiento territorial de provincias y regiones.

Los procesos de desarrollo económico suelen ser generadores de conflictos y desatar y sostener manifestaciones de violencia. Por ello resulta pertinente e incluso necesario considerar las instancias de participación en la planeación como parte de las infraestructuras de paz. Es aconsejable asumir el concepto de infraestructuras de paz como algo más que solo un conjunto de consejos y comités de paz, es decir, como algo más que un sistema complejo: como un sistema complejo adaptativo. Las infraestructuras de paz deben ser contempladas como plataformas amplias para la acción colectiva que, desde provincias y regiones, desarrollen relaciones formales e informales con organizaciones de base y con actores departamentales, nacionales e internacionales, que permitan coordinar decisiones, recursos y procesos para la construcción de paz.

Las infraestructuras de paz corresponden a un enfoque orientado a provocar esa transformación desde las comunidades en lugar de llevar las soluciones "desde afuera" de las propias comunidades: "soluciones" plagadas de problemas y con poco contenido emancipador que suelen dejar por fuera el conocimiento local e ignorar las particularidades de cada contexto. El territorio configura un contexto social porque es mucho más que un hecho geográfico. Tomando en cuenta la noción de espacio social de Di Meo \& Buleon, Chaparro \& Bouteille (2014: p. 19) afirman: "No hay territorio sin personas que lo usen e interactúen de forma individual y grupal dentro del mismo, es decir, no hay territorio sin actores". De lo que se desprende que tampoco hay territorios sin conflictos y por tanto se requieren estructuras apropiadas para su transformación. La fórmula del Estado unitario descentralizado es la fórmula de un Estado unitario en la imagen y fragmentado, diluido e incapaz en sus prácticas. En ese sentido, la reforma del ordenamiento territorial es necesaria para la gobernanza territorial —y policéntrica (Ostrom, 2009)— como transformación democrática de los conflictos en el territorio, en las escalas apropiadas.

\section{Comentario final}

La firma de un acuerdo de paz no es condición suficiente para asegurar la transición hacia una sociedad en paz. Es necesario desarrollar capacidades para 
transformar el conflicto armado y también los diferentes conflictos sociales que en los territorios podrían deslizarse hacia expresiones de violencia personal y directa. Esa es condición necesaria para una paz sostenible.

Un enfoque que integre la perspectiva holística y multinivel de construcción de paz planteada por John Paul Lederach, con una propuesta de gobernanza territorial basada en el andamiaje de provincias y regiones defendido por el sociólogo Orlando Fals Borda (1999), contribuiría a generar sinergias entre construcción de paz y construcción de Estado en una lógica democrática de abajo hacia arriba. Esa lógica posee mayor potencial emancipador y mejores posibilidades de pertinencia, legitimidad y eficacia, que la lógica tecnocrática de arriba hacia abajo propia de la paz liberal y el giro institucional. En la medida en que las infraestructuras de paz brindan un marco conceptual para visualizar la interdependencia de múltiples niveles en la sociedad, constituyen un mecanismo apropiado para complementar y apoyar la implementación del acuerdo de paz. Ello porque las infraestructuras de paz pueden ayudar a reducir la brecha entre el proceso de negociación política y las comunidades. En vista de las dificultades en la apropiación ciudadana del acuerdo de paz y la influencia política de sus saboteadores, la reducción de esa brecha debería de ser una prioridad en la fase de implementación.

\section{Referencias}

Barnett, M., Kim, H., O’Donnell, M. \& Sitea, L. (2007). Peacebuilding: What is in a name? Global Governance, (13), 35-58.

Bejarano, A. M. \& Pizarro, E. (2005). From "Restricted" to "Besieged". The Changing Nature of the Limits to Democracy in Colombia. En Mainwaring, S. \& Hagopian, F. (Eds.). The Third Wave of Democratization in Latin America. Advances and Setbacks (pp. 235-260). Cambridge: Cambridge University Press.

Boutros-Ghali, B. (1992). An Agenda for Peace. Nueva York: United Nations. Recuperado el 4 de septiembre de 2015, de http://www.un-documents.net/a47-277.htm

Call, C. (2008). Building States to Build Peace? A Critical Analysis. Journal of Peacebuilding and Development, 4(2), 60-74.

Call, C. \& Cousens, E. (2008). Ending Wars and Building Peace: International Responses to War-Torn Societies. International Studies Perspectives, 9(1), 1-21. 
Cederman, L., Gleditsch, K. \& Buhaug, H. (2013). Inequality, Grievances and Civil War. Nueva York: Cambridge University Press.

Chandler, J. (2010). A Rationale for Local Government. Local Government Studies, 36(1), 5-20.

Chang, H. (2010). Institutions and Economic Development: Theory, policy and history. Journal of Institutional Economics, 7(4), 473-498.

Chaparro, J. \& Bouteille, C. (2014). Participación en el ordenamiento y la planificación territorial en Colombia. Bogotá: Giz-Unión Europea. Mimeo.

Fals Borda, O. (1999). Guía práctica del ordenamiento territorial en Colombia: Contribución para la solución de conflictos. Análisis Político, (36), 82-101.

Galtung, J. (1969). Violence, peace, and peace research. Journal of Peace Research, 6(3), 167-191.

Gizelis, T, H. Dorussen, \& Petrova, M. (2016). Research Findings on the Evolution of Peacekeeping. Recuperado el 15 de septiembre de 2016, de http://repository.essex.ac.uk/16862/1/Gizelis -Dorussen-Petrova-Bound-to-Fail-MSS04a-to-AU-rev_.pdf

Goetze, C. \& Guzina, D. (2008). Peacebuilding, Statebuilding, Nationbuilding-Turtles All The Way Down?, Civil Wars, 10(4), 319-347.

Hall, P. \& Taylor, C. R. (1996). Political Science and the Three New Institutionalisms, Political Studies, (xLIV), 936-957.

Helmke, G. \& Levitsky, S. (2006). Introduction. En Gretchen, G. \& Levitsky, S. (Eds.). Informal Institutions and Democracy: Lessons from Latin America (pp. 1-30). Maryland: John Hopkins University Press.

Huntington, S. (1991). Democracys's Third Wave. Journal of Democracy, 2(2): 12-34.

Keen, D. (1998). The Economic Functions of Violence in Civil Wars. Nueva York: Oxford University Press/The International Institute for Strategic Studies.

Kliksberg, B. (2008). ¿Cómo enfrentar la inseguridad en América Latina? La falacia de la mano dura, Nueva Sociedad, (215), 4-16.

Ki-Moon, B. (2012). Peacebuilding in the aftermath of conflict. Nueva York: United Nations. Recuperado el 4 de agosto de 2014, de http://www.securitycouncilreport.org/atf/ cf/\%7B65BFCF9B-6D27-4E9C-8CD3-CF6E4FF96FF9\%7D/s_2012_746.pdf 
Lederach, J. (2012). The Origins and Evolution of Infrastructures for Peace: A Personal Reflection. Journal of Peacebuilding and Development, 7(3), 8-13.

Lederach, J. (2010). Building Peace. Sustainable Reconciliation in Divided Societies. Washington: United States Institute of Peace Press Books.

López Hernández, C. (2016). ¡Adiós a las Farc! ¿Y ahora qué? Construir ciudadania, Estado y mercado para unir las tres Colombias. Bogotá: Debate.

Mac Ginty, R. (2011). Hybrid peace: How does hybrid peace come about? En Campbell, S., Chandler, D. \& Sabaratnam, M. (Eds.). A liberal peace? The problems and practices of peacebuilding (pp. 209-225). Londres, Nueva York: Zed Books.

Malone, D. \& Nitzschke, H. (2009). Economic agendas in civil wars: What we know, what we need to know. En Addison, T. \& Brück, T. (Eds.). Making peace work: The challenges of social and economic reconstruction (pp. 31-50). Nueva York: Palgrave/Macmillan.

Migdal, J. (2001). The State in society. Studying how States and societies transform and constitute one another. Cambridge: Cambridge University Press.

Nafziger, E. \& Auvinen, J. (2001). Economic Development, Inequality, and Humanitarian Emergencies. WIDER. Recuperado de http://www.k-state.edu/economics/nafwayne/ ecdev10-1.pdf

Nasi, C. (2007). Cuando callan los fusiles. Impacto de la paz negociada en Colombia y Centroamérica. Bogotá: Norma/Universidad de los Andes.

Newman, E. \& Keller, N. (2007). Criminal legacies of war economies. Journal of Peacebuilding and Development, 3(3), 49-62,

Odendaal, A. (2012). South Africa’s infrastructure of peace. En Hancock, L. E. \& Mitchell, C. R. (Eds.). Local peacebuilding and national peace: Interaction between grassroots and elite processes (pp. 93-109). Londres, Nueva York: Bloomsbury Academic.

O’Donnell, G. (1993). Acerca del Estado, la democratización y algunos problemas conceptuales. Una perspectiva latinoamericana con referencias a países poscomunistas. Desarrollo Económico. Revista de Ciencias Sociales, 33(130), 163-184.

Ostrom, E. (2009). Beyond markets and States: Polycentric governance of complex economic systems. Prize Lecture. Tempe, AZ: Indiana University/Center for the Study of Institutional Diversity-Arizona State University. 
Paris, R. (2004). At war's end. Building peace after civil conflict. Cambridge: Cambridge University Press.

Pfeiffer. S. (2014). Infraestructura de paz en Colombia. Berlín: Berghof Foundation. Recuperado el 14 de diciembre de 2015, de https:/www.funcionpublica.gov.co/eva/admon/files/ empresas/ZW1wcmVzYV83Ng==/archivos/1462299931_9e5198db1f3b6cb52a5e7af5a 3c53778.pdf

Pierson, P. \& Skocpol, T. (2008). El institucionalismo histórico en la ciencia política contemporánea. Revista Uruguaya de Ciencia Politica, 17(1), 7-38.

Ryan, S. (2013). The evolution of peaebuilding. En Mac Ginty, R. (Ed.). Routledge Handbook of Peacebuilding (pp. 25-35). Londres, Nueva York: Routledge.

Ryan, J. (2012). Infrastructures for peace as a path to resilient societies: An institutional perspective. Journal of Peacebuilding \& Development, 7(3), 14-24.

Smoljan, J. (2003). The relationship between peace building and development. Conflict, Security and Development, 3(2), 233-255.

Stewart, F. (2009). Policies towards Horizontal Inequalities in Post-Conflict Reconstruction. En Addison, T. \& Brück, T. (Eds.). Making Peace Work: The Challenges of Social and Economic Reconstruction (pp. 146-174). Nueva York: Palgrave-Macmillan.

Torres Rivas, E. (2012). The Limits of Peace and Democracy in Guatemala. En Arnson, C. (Ed.). In the Wake of War. Democratization and Internal Armed Conflict in Latin America (pp. 79106). Washington: Woodrow Wilson Center Press.

Tilly, C. (2007). Democracy. Cambridge: Cambridge University Press.

Tilly, C. (1992). Coercion, Capital, and European States AD 990-1992. Malden, Massachusetts: Blackwell Publishing.

Uribe López, M. (2013a). La nación vetada: Estado, desarrollo y guerra civil en Colombia. Bogotá: Universidad Externado de Colombia.

Uribe López, M. (2013b). Civil Wars and Violent Peace in Africa and Latin America: A General Outlook. Africa Peace and Conflict Journal, 6(3), 50-63.

Recibido el 8 de enero de 2016. Aceptado el 14 de diciembre de 2016. 